\title{
Supervisão em terapia sexual no curso de pós-graduação latu-sensu em Terapia Sexual do Persona/SBRASH
}

Sonia Daud*

\section{RESUMO}

Terapeutas iniciantes, mas também aqueles com experiência clínica, procuram na supervisão uma forma de melhorar ou rever sua prática. A supervisão em terapia sexual pretende contribuir para a formação humana e profissional do terapeuta sexual. O Persona - Centro de Estudos do Comportamento Humano oferece, com o apoio da SBRASH, um curso específico de formação em terapia sexual, voltado para médicos e psicólogos. A supervisão ocupa o espaço central dessa formação.

Esse curso é oferecido durante um semestre letivo, sendo um encontro mensal, com dois dias de duração. O primeiro dia é mais voltado para os aspectos metodológicos da prática em terapia sexual, enquanto o segundo é inteiramente voltado para o atendimento e a supervisão. Os atendimentos de atores-pacientes são colhidos em vídeo, de forma a possibilitar

\footnotetext{
* Psicodrama e terapeura sexual Coordenadora do Curso de Terapia Sexual do Persona, com apoio da SBRASH.

Recebido em 07.07.98 Aprovado em 25.07.98
} 
aos terapeutas sexuais em formação uma visão mais ampla de sua forma de atuar. A supervisão em grupo permite uma riqueza de observação e de crescimento do profissional.

\section{INTRODUÇÃO}

\section{A supervisão na prática clínica}

A supervisão é o espaço no qual o terapeuta pode partilhar com outro terapeuta seu atendimento, de forma a obter um olhar diferente sobre si mesmo como profissional a assim crescer em sua profissão.

As pessoas que atuam em supervisão na área clínica devem ser bem preparadas e com grande experiência na atividade, além de dispor da habilidade de acolher o outro. Além dessa experiência profissional, é fundamental uma preparação didática que lhes permita estabelecer um intercâmbio com seus supervisionados.

Existem dois tipos de supervisão: a individual e a grupal. A segunda é mais rica, pois permite que cada terapeuta participante aproveite a vivência do colega. As questões relacionadas ao sigilo também colocam-se aqui, pois os supervisionados são profissionais que discutem seus atendimentos.

Para oferecer supervisão grupal, é importante que o supervisor saiba trabalhar com questões da interação grupal, estabelecendo bom vínculo para o grupo e no grupo. Por meio dessa interação, os supervisores trabalham as dificuldades pessoais e profissionais que cada supervisionando manifesta em seu atendimento. Dessa forma o supervisionando aprende a lidar com as frustrações trazidas pela crítica e consegue ver a si mesmo e a sua prática sob uma nova luz. Ao mesmo tempo, aprende por meio da experiência trazida pelo outro e a exercer a solidariedade.

O terapeuta iniciante não pode ficar sem supervisão: quem não faz supervisão não consegue formar um referencial de si mesmo e do que está fazendo como profissional, pois não tem parâmetros para isso. Esse referencial não depende apenas da supervisão e outras instâncias contribuem para ele, como congressos, simpósios, workshops, encontros... A participação nesses eventos possibilita uma atualização dos referenciais do terapeuta que, com o tempo, tem condições de reconhecer nos participantes quem evoluiu a quem não evoluiu; quem faz sempre as mesmas coisas e 
quem faz coisas diferentes; quem está contribuindo com novas visões para a atividade clínica. Possibilita também que o profissional reconheça o momento em que atinge o mesmo nível dos outros, a quem considera bons profissionais.

Na supervisão, parte-se do princípio de que tudo se aprende pela experiência ou do mais próximo possível da vivência. O supervisor é o terapeuta do terapeuta. Ele aborda como o terapeuta atua no seu campo profissional, como ele atua no seu consultório, por meio da discussão do supervisor discute o caso trazido para supervisão e trabalha as nuances da atividade do terapeuta, as angústias diante do outro, deixando emergir as fantasias, os temores. O terapeuta não pode trabalhar com seu paciente se está embotado ou se tem algum aspecto importante de sua vida mal trabalhado. O supervisor aborda o bloqueio de forma terapêutica, associando com a situação pessoal do supervisionando, mas sempre fazendo gancho com o paciente.

Por isso, a supervisão sempre é terapêutica. A diferença de uma psicoterapia é que ela não trabalha diretamente os problemas do indivíduo, mas sim como eles se manifestam na atividade profissional dele. A terapia é essencial, por permitir ao terapeuta, enquanto paciente, trabalhar suas questões pessoais.

Na supervisão, o profissional é trabalhado por dentro e por fora. Isso é, além da visão de mundo, do conhecimento teórico-prático, são também abordadas a postura corporal, a apresentação do consultório, a apresentação pessoal, as maneiras. O objetivo principal é trabalhar o profissional e, em segundo plano, o caso trazido por ele para discussão.

\section{A supervisão em terapia sexual}

Observa-se que, de maneira geral, grande parte dos terapeutas não aborda ou aprofunda o tema da sexualidade. Se o paciente traz algo, ele escuta, nem sempre se sentindo à vontade para perguntar. São poucos os que o fazem. Nem sempre se pergunta diretamente: Como está sua vida sexual?

Na supervisão em terapia sexual, cada terapeuta atua de acordo com sua própria linha teórica, com passos a serem cumpridos, que são as técnicas da terapia sexual. Tudo na dinâmica do paciente é associado com a queda sexual. Assim, no caso de supervisão grupal, podem participar terapeutas com linhas teóricas diferentes. Na supervisão individual, superior e supervisionando também podem seguir linhas teóricas diferentes. 
Dentre as várias técnicas de terapia sexual existentes, as mais usuais são as que se aplicam a cada disfunção específica. São técnicas de sensibilização, desenvolvida a partir de H. Kaplan e outros.

\section{O curso e a supervisão em terapia sexual no Persona}

A supervisão em grupos faz parte do currículo de pós-graduação latu-sensu em terapia sexual do Persona, com apoio da SBRASH.

Observa-se que a maioria dos médicos psiquiatras, ginecologistas ou urologistas e dos psicólogos chegam ao curso de terapia sexual muito constrangidos para falar de sexo, embora desejem superar essa dificuldade. Esse constrangimento é trabalhado no decorrer do curso, nas supervisões.

$\mathrm{O}$ curso é estruturado em encontros mensais, divididos em duas etapas, dadas em dois dias. O primeiro dia é de aquecimento. Além das aulas teóricas de orientação sobre as disfunções sexuais, realiza-se algum tipo de trabalho corporal e dinâmicas, como roleplaying, no qual o terapeuta vê a si mesmo como paciente e como profissional. O objetivo, além de formar e sensibilizar o grupo, é ajudar a pessoa a voltar a percepção para o próprio corpo, para as próprias sensações.

É importante lembrar que o profissional pode ter consultório há anos, como médico ou psicólogo, e não se sentir preparado para atuar como terapeuta sexual. Pode falar sobre sexo e ter intensa atividade sexual, mas não se sente preparado para ouvir alguém falar de problemas sexuais. Quando está diante do paciente, muitas vezes, o profissional sente-se travado.

A terapia e a supervisão proporcionam ao profissional o preparo para exercer a função de terapeuta sexual. Assim, ele pode entrar em contato com a própria sexualidade. Ninguém pode falar de sexo, abordar o tema ou trabalhar com ele se a sua própria sexualidade não está lúcida e presente. Para tratar o outro, o terapeuta precisa tratar de si mesmo.

O segundo dia é o da supervisão propriamente dita. São feitos dois atendimentos de meia hora cada um, seguidos de uma hora de supervisão. Isso se repete durante o dia todo. Durante o atendimento, não é feita qualquer interferência dos colegas ou do supervisor. O cursista é livre para conduzir o trabalho de forma que achar melhor.

O paciente é um ator ou atriz, preparado, treinado e acompanhado pela coordenação.

$\mathrm{Na}$ hora da supervisão, são discutidos os dois atendimentos, de acordo com os passos: 1) o co-supervisor A dá a palavra ao terapeuta $\mathrm{A}$, 
que diz como se sentiu e faz as observações que achar pertinentes; 2) o grupo discute o atendimento; 3) o co-superior fecha o caso, trabalhando o terapeuta enquanto profissional ( $80 \%$ do tempo) e o caso que esta sendo conduzido $(20 \%)$; 4) o supervisor faz o fechamento, com os últimos comentários (críticas e reforço) tanto à atuação do terapeuta quanto à do co-supervisor.

O processo é repetido com o co-supervisor B e o segundo atendimento. Essa sequiência ocorre quatro vezes no mesmo dia. Isto é, são atendidos e discutidos 8 casos por grupo. Cada participante tem a oportunidade de aprendizado por três ângulos. Primeiro, ele é trabalhado na interação grupal, como um dos elos da corrente. Segundo, no papel de profissional, como terapeuta, ele é avaliado e seu atendimento, discutido. Por último, vai observar como a atuação do co-supervisor é analisada pelo supervisor. Dessa forma, aprende como é feito o manejo do grupo.

Um dos aspectos trabalhados é o impacto sofrido pelo profissional no seu primeiro atendimento em terapia sexual, em tudo diferente do que está acostumado. Até a amamnese é específica, porque voltada para a disfunção.

Outro aspecto de grande valia é que os atendimentos são gravados em vídeo e cada cursista tem sua própria fita. Foi realizado um curso sem gravação e três com gravação e a experiência mostrou que o vídeo ajuda o profissional em formação. Este pode se sentir injustiçado na discussão ou não se dar conta de muita apontada pelo grupo, pelo co-supervisor ou pelo supervisor. Leva então a fita de vídeo para a casa e pode ver e ouvir o que aconteceu: sua postura corporal, a fala, com seus vícios de linguagem, as intervenções, etc. Na supervisão seguinte, ele chega menos defendido e mais tolerante, tornando-se mais receptivo ao aprendizado. $\mathrm{O}$ cursista traz sua fita toda vez que vier para o curso e ao final fica com a gravação dos quatro ou cinco atendimentos que fez.

O clima da supervisão é muito bom. Só o primeiro dia é mais tenso, pois tudo ainda é muito novo. No terceiro, o grupo já está bem integrado e atuando de forma coesa. A partir desse momento, o curso torna-se muito gostoso, pois a quebra das resistência favorece a emergência da afetividade.

Um aspecto importante a ser ressaltado é que os pacientes são de todos os cursistas, de forma que a solidariedade se desenvolve entre os membros do grupo. Ao final do curso, cada terapeuta entrega relatório de um paciente, de todos os atendimentos, isto é, não há processo individua- 
lizado. Todos se interessam e se envolvem com todos os pacientes, em todos os atendimentos.

Os atendimentos seguem uma seqüência: da primeira sessão até a possível alta.

\section{REFERÊNCIAS BIBLIOGRÁFICAS}

1. CALIL, V. L. Terapia sexual e de casal. Summus, São Paulo, 1987.

2. CAVALCANTI, R. e CAVALCANTI, M. Inadequações sexuais. Roca, São Paulo, 1992.

3. CAVAlCANTI, R. e VITIELlO, N. Sexologia I. 2. ed. CEICH, São Paulo, 1997.

4. CHAUÍ, M. Repressão sexual - essa nossa (des)conhecida. Brasiliense, São Paulo, 1991. 12. ed.

5. FUCS, G. B. Homem/mulher \& encontros e desencontros. Rosa dos Tempos, Rio de Janeiro, 1992.

6. HEIMAN, J.; Lo PICCOLlO, L.; Lo PICCOLlO, J. Descobrindo o prazer uma proposta sexual para a mulher. Summus, São Paulo, 1981.

7. HERRIN, K. O livro de sexo - exercícios. Roca, São Paulo, 1984.

8. KAPLAN, H. A nova terapia do sexo. 4. ed., Nova Fronteira, Rio de Janeiro, 1977.

9. KAPLAN, H. Desejo sexual. Nova Fronteira, Rio de Janeiro, 1983.

10. KOLODNY, R. C.; MASTERS, W. H. e JOHNSON, V. E. Manual de medicina sexual. Manole, São Paulo, 1982.

11. KUSNETZOFF, J. C. A mulher sexual feliz. Nova Fronteira, Rio de Janeiro, 1988.

12. KUSNETZOFF, J. C. O homem sexualmente feliz. Nova Fronteira, Rio de Janeiro, 1990.

13. LOPES G. P. \& cols. Patologia e terapia sexual. Medsi, Rio de Janeiro, 1994.

14. MANNOCCI, J. F.; RODRIGUES JR., O. M.; CONCEIÇÃO, I. S. C. e VITIELLO, N. Disfunções sexuais: abordagem clínica e terapêutica. Fundo Editorial BYK, São Paulo, 1995.

15. MASTERS, W. H. e JOHNSON, V. E. A inadequação sexual humana. Roca, São Paulo, 1985.

16. MUNJACK, D. J. e OZIEL, L. J. Sexologia, diagnóstico e tratamento. Atheneu, Rio de Janeiro, São Paulo, 1984.

17. PUECH-LEÃO, P.; GLINA, S. Os órgãos de Adão. Marco Zero, São Paulo, 1990.

18. RODRIGUES JR., O. M. Psicologia e sexualidade. São Paulo, Medsi, 1995.

19.VITIELlo, N. Sexologia II. 2. ed. CEICH, São Paulo,1997.

20.VITIELLO, N. e RODRIGUES JR., O. M. As bases anatômicas e funcionais do exercício da sexualidade. Iglu, São Paulo, 1997.

21. VITIELLO, N.; OLIBONI, E. R. D.; S. e YABUSAKI, E. T. Afinal, o que é terapia sexual? RBSH 9(1):15-7, 1998. 